\title{
Effect of different nucleating agent on crystallization kinetics and morphology of polypropylene
}

https://doi.org/10.1515/epoly-2019-0005

Received June 15, 2018; accepted December 10, 2018.

Abstract: The effects of phosphate nucleating agent (NA), carboxylate nucleating agent (MD), rosin type nucleating agent (WA) and sorbitol nucleating agent (NX) on crystallization behavior of isotactic polypropylene were investigated by fourier transform infrared spectroscopy (FTIR), X-ray diffraction (XRD), differential scanning calorimetry (DSC) and polarized light microscopy (PLM). The results showed that different structure nucleating agents significantly affected the crystallization kinetics, rate and temperature of polypropylene. Among them, half crystallization time of NX nucleating agent was the shortest, which was 53.4 seconds, and the crystallization temperature was the highest, reaching $129.8^{\circ} \mathrm{C}$.

Keywords: polypropylene; crystallization kinetics; nucleating agent

\section{Introduction}

Polypropylene (PP) has good physical \& mechanical properties and excellent processing performance, and has become the most developed and fastest growing polymer of the five general synthetic ones. Because polypropylene is a semi-crystalline polymer, people usually add a certain amount of nucleating agent to improve its crystalline morphology, and realize its functionalization. At present, nucleating agent can be divided into alpha, beta and gamma nucleating agent (1-3), according to the crystal form. Different kinds of nucleating agents can improve the crystallization rate of polypropylene in the forming

\footnotetext{
* Corresponding authors: Yanjie An, Daqing Petrochemical Research Center, Petrochemical Research Institute of Petrochina, Daqing, Heilongjiang, People’s Republic of China, e-mail: ayj459@ petrcochina.com.cn, tel:+86-459-6765132.

Sihan Wang, Rui Li, Dezhu Shi, Yuxin Gao and Lei Song, Daqing Petrochemical Research Center, Petrochemical Research Institute of Petrochina, Daqing, Heilongjiang, People's Republic of China.
}

process and refine the crystallization, thus improving the comprehensive properties of the material such as toughness, transparency and glossiness. The formation of network structure of sorbitol, which is one of the most common nucleating agents $(4,5)$, can induce the crystallization of polypropylene.

At present, some researchers have studied crystallization behavior, crystal forms, crystal morphology, and solar reflectance of polypropylene (6-14). At the same time, the effect of non-isothermal crystallization kinetics, isothermal crystallization kinetics and crystallization rate of PP, has also been investigated to a certain extent (15-19).

In this works, the effects of phosphate nucleating agent (NA), carboxylate nucleating agent (MD), rosin nucleating agent (WA) and sorbitol nucleating agent (NX) on the crystallization kinetics, rate and temperature of PP were studied. The morphology of nucleated polypropylene was investigated by polarizing microscope.

\section{Experimental}

\subsection{Materials}

Homogeneous PP powder (Daqing petrochemical company, China) was blended with different kinds of nucleating agent. Carboxylate nucleating agent (MD), rosin nucleating agent (WA), Sorbitol nucleating agent (NX) and Phosphate nucleating agent (NA), were purchased from Mudanjiang Beida fine chemical plant (China), Zhejiang Wanan plastic co., ltd. (China), American Milliken chemical company (America) and Asahi chemical co., ltd. (Japan), respectively.

\subsection{Preparation of sample}

Polypropylene powder and four different kinds of nucleating agents were respectively added into a highspeed mixer according to a fixed proportion for mixing. The mixture was melt extrude and pelletized in TSSL-25 
corotating twin-screw extruder with a diameter of $25 \mathrm{~mm}$ and a length/diameter ratio of $36 / 1$. The screw configuration was designed to provide better mixing and refining dispersion. The barrel temperatures from the feed zone to the die one were set as follows: 190, 210, 220, 220, 220, 220, 210, 200 and $195^{\circ} \mathrm{C}$. The screw rate and feed rate were kept constant at $65 \mathrm{rpm}$ and $21 \mathrm{rpm}$, respectively. The sample sheet with a specified thickness of $1 \mathrm{~mm}$ was prepared on a flat vulcanizing machine for mechanical property testing.

\subsection{Charaterization}

The infrared spectrum in the range of $600 \sim 4000 \mathrm{~cm}^{-1}$ was recorded by a FTIR spectrometer (Mod. SPECTRUM GX 2000, Perkin/Elmer Ltd., Beacons-field, Buckshire, UK), and the resolution was $4 \mathrm{~cm}^{-1}$. Samples for FTIR measurements were prepared by realizing films of PP pellets, which were $30 \mathrm{um}$ thick by hot pressing at $210^{\circ} \mathrm{C}$. According to the FTIR spectrum, the crystallinity can be calculated with the Eq. 1, wherein $\mathrm{k}$ is a constant, and for convenience of comparison, $\mathrm{k}$ is set to 1 , and a crystallization spectrum band $998 \mathrm{~cm}^{-1}$ and an amorphous spectrum band $1460 \mathrm{~cm}^{-1}$ related to a long spiral segment are selected as internal standards for measuring the crystallinity of the PP film, and $\mathrm{A}_{998}$ and $\mathrm{A}_{1460}$ is at the wave numbers $998 \mathrm{~cm}^{-1}$ and $1460 \mathrm{~cm}^{-1}$, respectively (20).

$$
\mathrm{Xc}=\mathrm{k} \times \frac{\mathrm{A}_{998}}{\mathrm{~A}_{1460}}
$$

At room temperature, a wide-angle X-ray diffraction (WAXD) measurement was performed by the $\mathrm{D} / \mathrm{max}$ 2500/PC X-ray diffractometer (Rigaku, Japan), which used $\mathrm{CuK \alpha}$ radiation operated at $35 \mathrm{kV}$ and $50 \mathrm{~mA}$. The data were collected from $6^{\circ}$ to $50^{\circ}$ at $3^{\circ} / \mathrm{min}$ scanning rate. All samples were treated uniformly before testing. According to the XRD spectrum, the integral strength of all crystal sharp diffraction peaks and amorphous diffuse scattering peaks can be calculated by using a computer peak splitting program, and the crystallinity can be calculated according to Eq. 2, wherein Xc represents the crystallinity, Ic represents the integral strength of crystal sharp diffraction peak, and Ia represents the integral strength of amorphous diffuse scattering peak (21).

$$
\mathrm{Xc}=\mathrm{Ic} /(\mathrm{Ic}+\mathrm{Ia}) \times 100 \%
$$

For the calorimetric investigation, about $6 \mathrm{mg}$ of PP sample was weighed in Sealed aluminum foil, which is then heated from $50^{\circ} \mathrm{C}$ to $200^{\circ} \mathrm{C}$ using a Perkin - Elmer Pxrisl type differential scanning calorimeter under $\mathrm{N}_{2}\left(50 \mathrm{ml} / \mathrm{min}\right.$ of gas flow), and kept at $200^{\circ} \mathrm{C}$ for $5 \mathrm{~min}$ (to eliminate thermal history and make it completely molten), and then DSC curves of various polypropylene samples at $10^{\circ} \mathrm{C} / \mathrm{min}$ were obtained. The degree of crystallinity of PP was calculated by the Eq. 3, wherein Xc represents the crystallinity, wherein $\Delta \mathrm{H}_{\mathrm{m}}$ represents the melting enthalpy of PP samples, $\Delta \mathrm{H}_{0}$ represents the melting enthalpy of PP samples with crystallinity of 100\% ( $207 \mathrm{~J} / \mathrm{g}$ ) (22).

$$
\mathrm{X}_{\mathrm{c}}=\Delta \mathrm{H}_{\mathrm{m}} / \Delta \mathrm{H}_{0}
$$

For the isothermal crystallization: about $6 \mathrm{mg}$ of PP sample was weighed in a crucible, and the sample was rapidly heated from $50^{\circ} \mathrm{C}$ to $200^{\circ} \mathrm{C}$ using a Perkin Elmer Pxrisl type differential scanning calorimeter under $\mathrm{N}_{2}\left(50 \mathrm{ml} / \mathrm{min}\right.$ of gas flow), and kept at $200^{\circ} \mathrm{C}$ for 5 min (to eliminate heat history and make it completely molten), and quickly cooled sample to a set temperature $\left(110-140^{\circ} \mathrm{C}\right)$, and kept at the constant temperature until crystallization was completed, and then DSC curves of various polypropylene samples were obtained.

There are many other equations able to perform kinetics studies on the crystallization of polymer as shown in Eq. 4, in which $X_{t}$ represents the relative crystallinity of the crystallization time of $t, Z_{t}$ is the crystallization rate constant, which is related to nucleation rate and crystallization rate, $\mathrm{n}$ is Avrami index, which represents the crystallization nucleation and growth mechanism of the polymer.

$$
1-X_{t}=\exp \left(-Z_{t} t^{n}\right)
$$

The logarithm of the above formula is taken to obtain Eq. 5.

$$
\ln \left[-\ln \left(1-X_{t}\right)\right]=\ln Z_{t}+n \ln t
$$

According to the plot of $\ln \left(-\ln \left(1-\mathrm{X}_{\mathrm{t}}\right)\right)$ and $1 \mathrm{nt}$, the linear slope $\mathrm{n}$ and intercept $1 \mathrm{n} \mathrm{Z}_{\mathrm{t}}$ can be calculated by the linear equation, and the values of $\mathrm{n}$ and $\mathrm{Z}_{\mathrm{t}}$ can also be calculated, thus obtaining the information on the crystallization growth of polypropylene.

According to the non-isothermal crystallization DSC curve, the relative crystallinity $\mathrm{X}_{\mathrm{t}}$ at any crystallization temperature can be calculated by Eq. 6. In the Eq. 6, $\mathrm{T}_{0}$ represents the temperature at the beginning of crystallization, $\mathrm{T}_{\infty}$ represents the temperature at the completion of crystallization, $\mathrm{T}$ represents the crystallization temperature, and $\mathrm{H}$ represents the enthalpy 
of crystallization. By time-temperature conversion, the Avrami equation can be used to calculate the relationship between the non-isothermal crystallization time $t$ and the relative crystallinity $\mathrm{X}_{\mathrm{t}}(23,24)$.

$$
X_{t}=\int_{T_{0}}^{\mathrm{T}}(d H / d T) d T / \int_{T_{0}}^{\mathrm{T}_{\infty}}(d H / d T) d T
$$

For isothermal crystallization kinetics, $\mathrm{X}_{\mathrm{t}}$ is defined as Eq. 7 (25-27).

$$
X_{t}=\int_{0}^{t}(d H / d t) d t / \int_{0}^{\infty}(d H / d t) d t
$$

$\mathrm{dH} / \mathrm{dt}$ is the heat flow rate and $\mathrm{X}_{\mathrm{t}}$ is the crystallinity at time $t$. The relationship between the relative crystallinity $t$ and $X_{t}$ can be obtained by integrating the DSC curve with the crystallization time t. Using $1 \mathrm{n}\left(-1 \mathrm{n}\left(1-\mathrm{X}_{\mathrm{t}}\right)\right)$ to plot $1 \mathrm{nt}$, the linear slope $n$ and intercept $1 \mathrm{nZ}_{\mathrm{t}}$ can be obtained from the linear equation, and then the values of $Z_{t}$ and $n$ can be obtained.

PLM polarizing microscope measurements were performed by XP-201 polarization microscope test. Firstly, the prepared $0.5 \mathrm{~mm}$ sheet was placed on a constant temperature slide of an electric furnace at $260^{\circ} \mathrm{C}$, and the cover slide was added after melting, and the temperature was kept for 1 minute, and then the $0.5 \mathrm{~mm}$ sheet was quickly put into an oven at $140^{\circ} \mathrm{C}$, and crystallized for $1 \mathrm{~h}$, and then taken out.

According to X-ray diffraction theory, the crystal size can be calculated by Debye-Scherrer formula (Eq. 8 and 9) (28), as shown in Eq. 8, where $\lambda=$ incident wavelength, $\mathrm{D}=$ grain diameter, $\beta_{\mathrm{hkl}}$ = half peak width of diffraction peak, $\theta=$ diffraction angle, wherein $\lambda$ is $0.15406 \mathrm{~nm}, \mathrm{k}=0.9$, $\beta_{\mathrm{hkl}}=\beta^{\star} 2 \pi / 360$ (converted to radians).

$$
\begin{gathered}
\mathrm{D}=\frac{\mathrm{k} \lambda}{\beta_{\mathrm{hkl}} \cos \theta} \\
\mathrm{D}=\frac{0.9^{\star} 0.15406 * 360 / 2 \pi}{\beta \cos \theta} \quad \mathrm{D}=\frac{7.94832}{\beta \cos \theta}
\end{gathered}
$$

Crystal nucleus density, which is a physical quantity to express the size of polymer spherulites, refers to the number of crystal nuclei in the unit volume, can be calculated directly from the average spherical crystal diameter. The calculation Eq. 10 is:

$$
\mathrm{ND}=\frac{1}{4 / 3 \pi(\mathrm{R} / 2)^{3}}
$$

\section{Results and discussion}

\subsection{Effect of nucleating agent on crystallinity of polypropylene}

Four modified polypropylene samples were tested by FTIR (as shown in Figure 1), XRD (as shown in Figure 2) and DSC. DSC melt enthalpy data of four modified PP were shown in Table 1. According to Eq. 1-3, the respective crystallinity was calculated.

The crystallinity calculated by various test methods is shown in Table2. Four nucleating agents make the crystalline core of PP easier to form, and significantly increase the
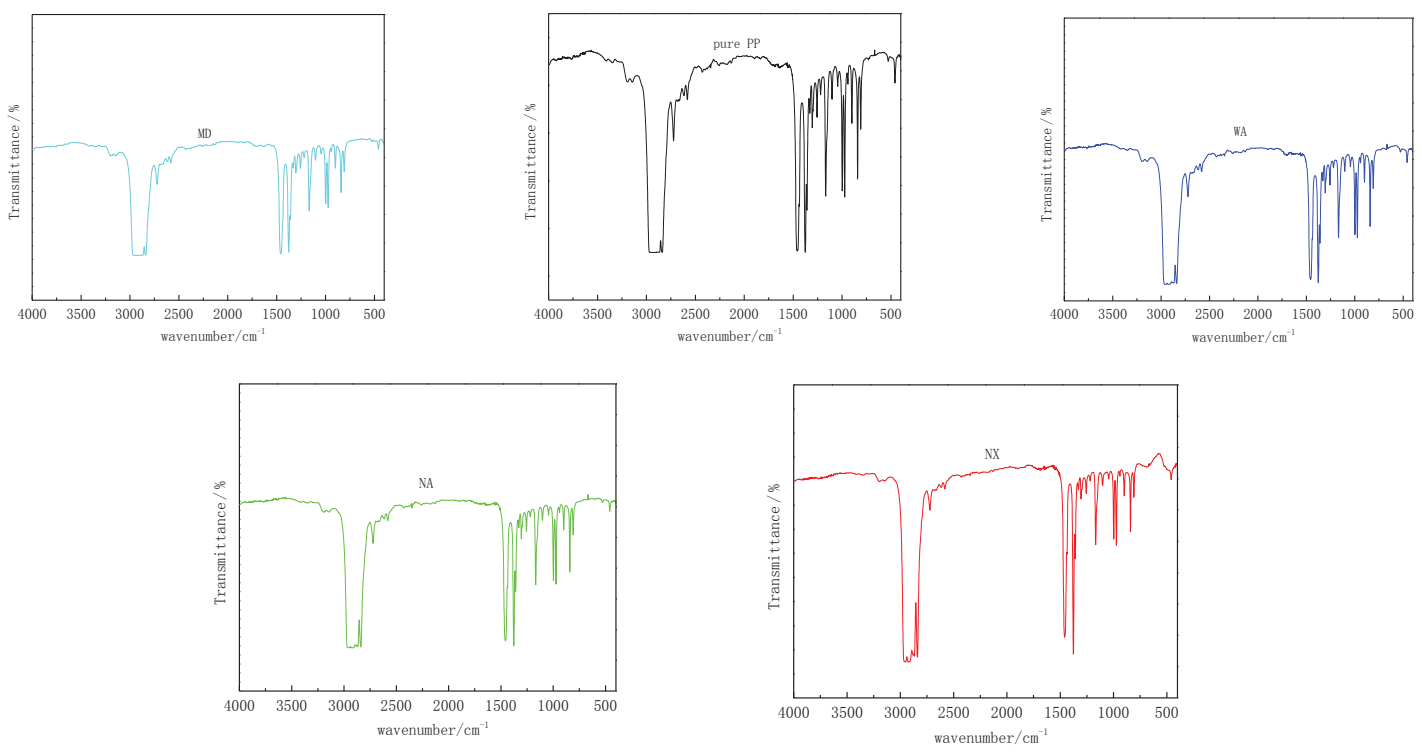

Figure 1: Infrared spectra of modified PP. 


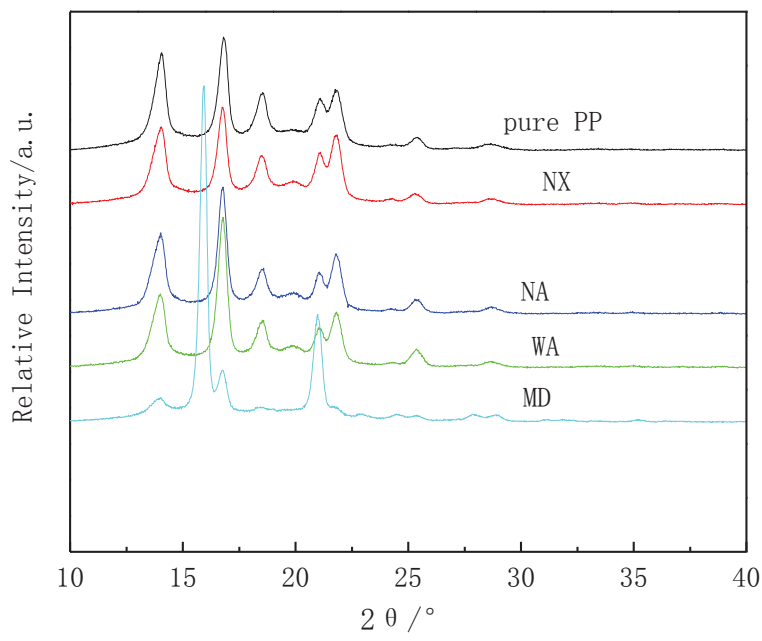

Figure 2: XRD spectra of modified PP.

Table 1: Melting enthalpy data of modified PP.

\begin{tabular}{lrrrrr}
\hline No & Pure PP & NX & NA & WA & MD \\
\hline$\Delta \mathrm{H}_{\mathrm{m}} / \mathrm{J} \cdot \mathrm{g}^{-1}$ & 90.11 & 95.98 & 94.33 & 93.59 & 90.99 \\
\hline
\end{tabular}

Table 2: The crystallinity of PP.

\begin{tabular}{llrrr}
\hline No & Nucleating agent & Infrared/\% & XRD/\% & DSC/\% \\
\hline 1 & Pure pp & 39.65 & 36.22 & 43.53 \\
2 & NX & 47.44 & 63.25 & 46.37 \\
3 & NA & 45.27 & 55.69 & 45.57 \\
4 & WA & 43.68 & 54.17 & 45.21 \\
5 & MD & 41.55 & 41.14 & 43.95 \\
\hline
\end{tabular}

crystallinity of PP, in which the crystallinity of the modified PP prepared with NX nucleating agent increased greatly.

\subsection{Effect of nucleating agent on non-isothermal crystallization kinetics of polypropylene}

According to the non-isothermal crystallization DSC curves (as shown in Figure 3, the cooling rate was $10^{\circ} \mathrm{C} / \mathrm{min}$ ), the relative crystallinity $\mathrm{X}_{\mathrm{t}}$ at any crystallization temperature can be calculated by Eq. 6. By time-temperature conversion, the Avrami equation can be used to calculate the relationship between the non-isothermal crystallization time $t$ and the relative crystallinity $\mathrm{X}_{\mathrm{t}}$, as shown in Figure 4.

According to Eq. 4 and 5, 1nt is plotted with $\mathrm{n}\left(-1 \mathrm{n}\left(1-\mathrm{X}_{\mathrm{t}}\right)\right)$, and the curve relationship is shown in Figure 5. It can be seen from the figure that $\ln \left(-\ln \left(1-X_{t}\right)\right)$ has a good linear relationship with 1nt, only at high crystallinity, the data points deviate from the linear

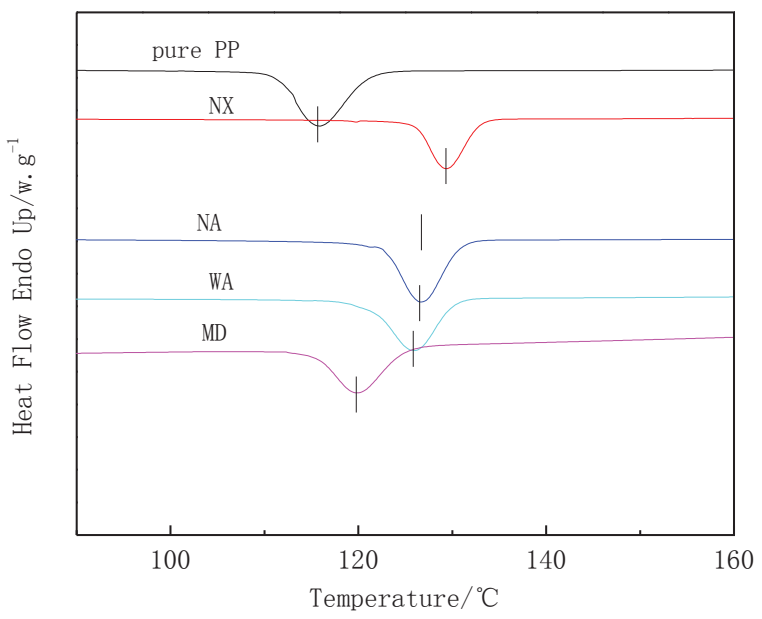

Figure 3: Non-isothermal crystallization DSC curve of nucleated polypropylene.

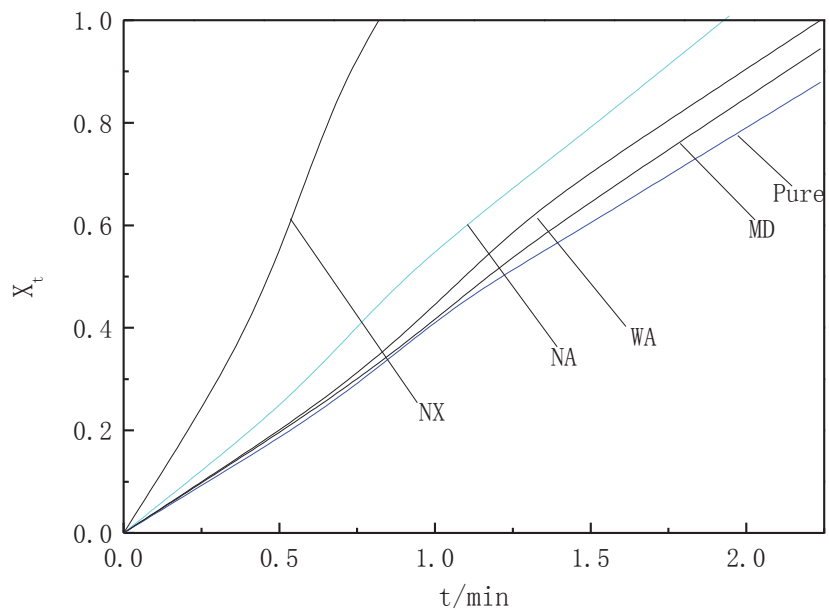

Figure 4: Non-isothermal crystallization curve relative crystallinity fraction.

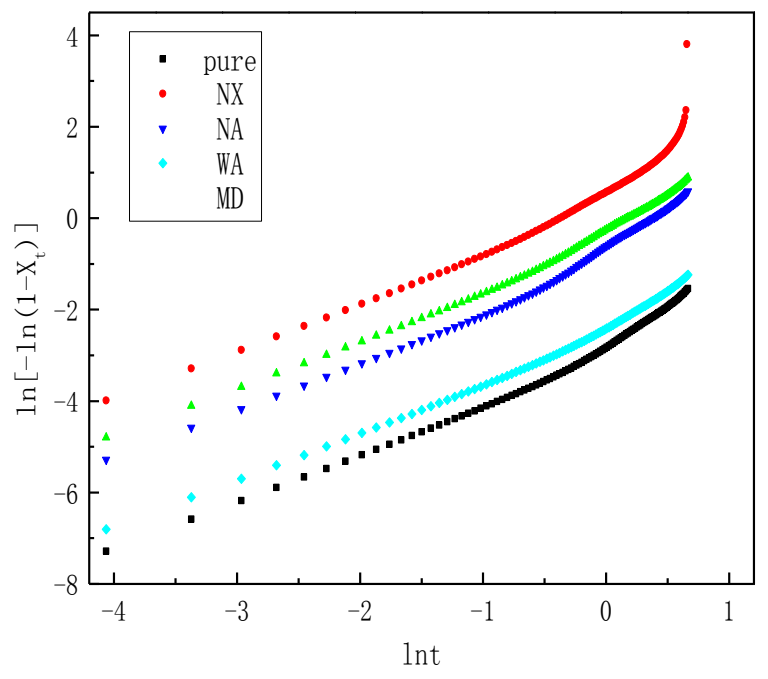

Figure 5: Non-isothermal crystallization $\ln (-\ln (1-\mathrm{Xt}))$ on a linear relationship Int. 
law. The rate constants $Z_{t}$ and Avrami exponent $n$ are calculated by slope and intercept. According to the correction of cooling rate, that is, $\ln Z_{c}=\ln Z_{\mathrm{t}} / \varphi$, the rate constant $Z_{c}$ of the non-isothermal crystallization process can be calculated, and the calculation results are shown in Table 1. When $X_{t}=50 \%$, the half crystallization time $t_{1 / 2}$ can also be calculated according to the calculation formula $t_{1 / 2}=\left(\ln 2 / Z_{t}\right)^{1 / n}$.

$Z_{c}$ is a non-isothermal crystallization kinetic rate constant, and the larger the value, the faster the crystallization rate of polypropylene is. It can be seen from Table 3, the $\mathrm{n}$ value of each modified polypropylene is not different, which indicates that each nucleating agent makes the polypropylene exhibit heterogeneous crystallization, and changes the crystallization nucleation and growth mode of the polypropylene. Compared with other nucleating agents, NX nucleating agents significantly increase the crystallization rate of polypropylene.

\subsection{Effect of nucleating agent on isothermal crystallization kinetics of polypropylene}

According to isothermal crystallization curve and Eq. 7, the relationships between crystallization time $\mathrm{t}$ at different crystallization temperatures and relative crystallinity $\mathrm{X}_{\mathrm{t}}$ can be obtained by integrating DSC curves

Table 3: Parameters of non-isothermal crystallization kinetics.

\begin{tabular}{lrrrrr}
\hline & $\mathbf{n}$ & $\ln \mathbf{Z}_{\mathbf{t}}$ & $\mathbf{Z}_{\mathbf{c}}$ & $\mathbf{Z}_{\mathbf{t}} / \mathbf{m i n}^{-\mathbf{n}}$ & $\mathbf{t}_{1 / 2} / \mathbf{s e c}$ \\
\hline Pure PP & 1.22 & -0.61 & 0.9403 & 0.5406 & 73.2 \\
NX & 1.13 & -0.23 & 0.9764 & 0.7875 & 53.4 \\
NA & 1.09 & -0.46 & 0.9547 & 0.6288 & 65.4 \\
WA & 1.11 & -0.48 & 0.9527 & 0.6151 & 66.6 \\
MD & 1.29 & -0.55 & 0.9460 & 0.5738 & 69.0 \\
\hline
\end{tabular}

of different nucleating agents modified polypropylene (Figure 6).

The crystallization time of modified polypropylene increases with the increase of crystallization temperature, which indicates that the crystallization rate of modified PP decreases gradually. Meanwhile, compared with pure PP, nucleating agent can greatly reduce the semicrystallization time and increase the crystallization rate of polypropylene, thus shortening the forming and processing period of the product. According to Eq. 5, $\ln \left(-\ln \left(1-\mathrm{X}_{\mathrm{t}}\right)\right)$ was plotted as shown in Figure 7.

There is a good linear relationship between $\ln \left(-\ln \left(1-X_{t}\right)\right)$ and $\ln _{t}$. The rate constants $Z_{t}$ and Avrami exponent $\mathrm{n}$ can be obtained from the intercept and slope of the curve, so that $X_{t}=50 \%$, and the half crystallization time $t_{1 / 2}$ can be calculated. The specific numerical values are shown in Table 4.

Table 4 that Avrami index has little change at different temperatures, indicating that nucleating agent has little effect on the crystallization mode of polypropylene. The crystallization rate constant $Z_{t}$ decreases with the increase of crystallization temperature, which indicates that the crystallization temperature increases, and the growth rate and nucleation rate both decrease. In addition, the addition of nucleating agent shortens the semicrystallization time, in which the semi-crystallization time of NX-modified polypropylene is $4.12 \mathrm{~min}$, and the kinetic constant $Z_{t}$ value is 0.106 , which indicates that NX-nucleating agent has good nucleating effect.

\subsection{Effect of nucleating agent on crystallization rate of polypropylene}

At present, the crystallization rate is characterized by $\mathrm{t}_{1 / 2}$ (semi-crystallization time), $\Delta \mathrm{T}_{\mathrm{c}}$ (difference between initial

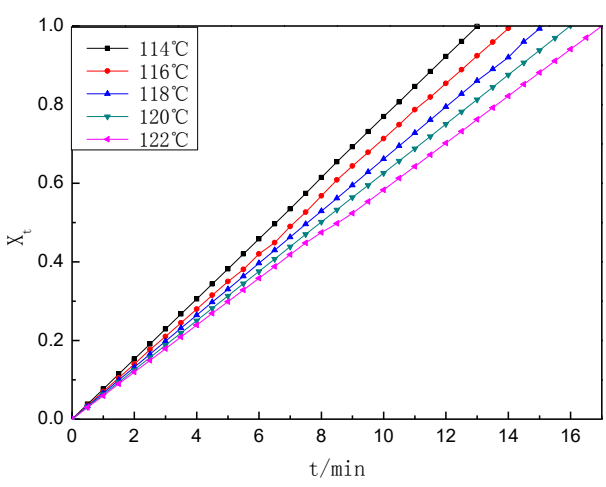

(a) pure

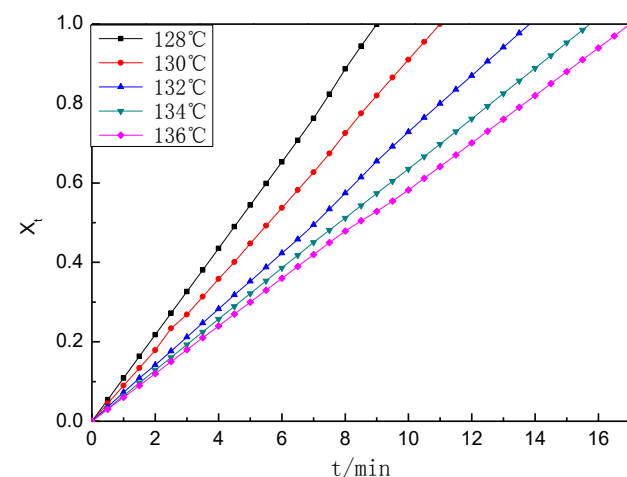

(b) NX

Figure 6: Isothermal crystallization relative crystallinity fraction curve. 


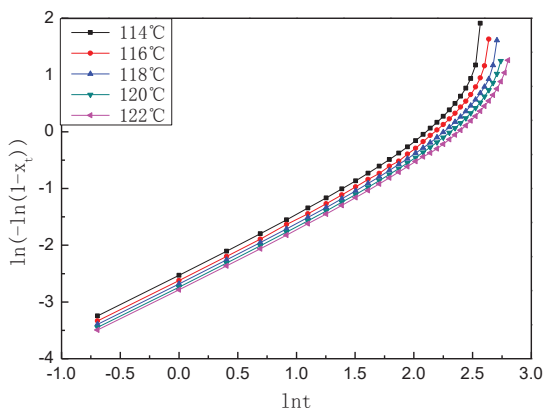

(a) pure

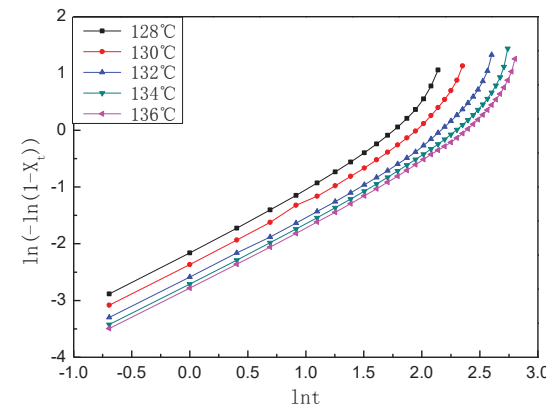

(b) NX

Figure 7: Isothermal crystallization $\ln (-\ln (1-\mathrm{Xt}))$ on a linear relationship Int.

Table 4: Isothermal crystallization kinetics parameters.

\begin{tabular}{|c|c|c|c|c|c|}
\hline & $\mathrm{T}_{\mathrm{c}} /{ }^{\circ} \mathrm{C}$ & $\mathrm{n}$ & $\ln Z_{t}$ & $\mathrm{Z}_{\mathrm{t}} / \mathrm{min}^{-\mathrm{n}}$ & $t_{1 / 2} / \mathrm{sec}$ \\
\hline \multirow{5}{*}{ Pure PP } & 114 & 1.37 & -2.73 & 0.065 & 30.9 \\
\hline & 116 & 1.36 & -2.82 & 0.059 & 37.5 \\
\hline & 118 & 1.34 & -2.89 & 0.055 & 43.4 \\
\hline & 120 & 1.30 & -2.92 & 0.054 & 49.4 \\
\hline & 122 & 1.29 & -2.97 & 0.051 & 56.0 \\
\hline \multirow{5}{*}{ NX } & 128 & 1.32 & -2.23 & 0.106 & 17.0 \\
\hline & 130 & 1.32 & -2.48 & 0.084 & 24.2 \\
\hline & 132 & 1.33 & -2.77 & 0.062 & 37.3 \\
\hline & 134 & 1.32 & -2.90 & 0.055 & 46.1 \\
\hline & 136 & 1.29 & -2.96 & 0.051 & 56.4 \\
\hline \multirow{5}{*}{ NA } & 128 & 1.38 & -2.40 & 0.090 & 19.1 \\
\hline & 130 & 1.33 & -2.73 & 0.065 & 34.6 \\
\hline & 132 & 1.32 & -2.76 & 0.063 & 36.8 \\
\hline & 134 & 1.34 & -2.92 & 0.054 & 44.4 \\
\hline & 136 & 1.29 & -2.98 & 0.051 & 55.7 \\
\hline \multirow{5}{*}{ WA } & 126 & 1.32 & -2.39 & 0.091 & 21.3 \\
\hline & 128 & 1.32 & -2.43 & 0.088 & 22.4 \\
\hline & 130 & 1.32 & -2.64 & 0.071 & 31.2 \\
\hline & 132 & 1.30 & -2.82 & 0.059 & 43.3 \\
\hline & 134 & 1.29 & -2.96 & 0.051 & 56.6 \\
\hline \multirow{4}{*}{ MD } & 128 & 1.32 & -2.70 & 0.068 & 33.2 \\
\hline & 130 & 1.33 & -2.86 & 0.057 & 42.4 \\
\hline & 132 & 1.32 & -2.95 & 0.052 & 50.4 \\
\hline & 134 & 1.28 & -2.95 & 0.052 & 55.7 \\
\hline
\end{tabular}

crystallization temperature $T_{c}{ }_{c}$ and peak temperature $T_{c}{ }^{p}$ ), and S (initial slope of crystallization peak). These three kinetic rate parameters are obtained by DSC test. $t_{1 / 2}$ is calculated by avramni equation. According to Figure $3, \mathrm{t}_{1 / 2}$, $\Delta \mathrm{T}_{\mathrm{c}}, \mathrm{S}$ and other parameters are shown in Table 5.

$\Delta \mathrm{T}_{\mathrm{c}}$ value represents the crystallization rate. The smaller the value is, the faster the crystallization rate goes. From Table 5, the crystallization parameters of the modified
Table 5: The effect of nucleating agent on polypropylene crystallization rate.

\begin{tabular}{llrrrrr}
\hline NO & $\begin{array}{l}\text { Type of nucle- } \\
\text { ating agent }\end{array}$ & $\mathbf{T}_{\mathrm{c}}{ }^{\text {on }} /{ }^{\circ} \mathbf{C}$ & $\mathbf{T}_{\mathrm{c}}{ }^{\mathrm{P}} /{ }^{\circ} \mathbf{C}$ & $\boldsymbol{\Delta T}_{\mathrm{c}} /{ }^{\circ} \mathbf{C}$ & $\mathbf{S}$ & $\mathbf{t}_{1 / 2} / \mathbf{s e c}$ \\
\hline 1 & Pure PP & 125.8 & 115.8 & 10.0 & 0.23 & 73.2 \\
2 & NX & 135.7 & 129.8 & 5.9 & 0.31 & 53.4 \\
3 & NA & 134.2 & 127.1 & 7.1 & 0.29 & 65.4 \\
4 & WA & 133.7 & 125.9 & 7.8 & 0.27 & 66.6 \\
5 & MD & 129.7 & 120.3 & 9.4 & 0.24 & 69.0 \\
\hline
\end{tabular}

Table 6: The crystallization temperature and melting temperature.

\begin{tabular}{llrl}
\hline No & Type of nucleating agent & $\mathrm{T}_{\mathrm{c}} /{ }^{\circ} \mathrm{C}$ & $\mathrm{T}_{\mathrm{m}} /{ }^{\circ} \mathrm{C}$ \\
\hline 1 & Pure PP & 115.8 & 165.1 \\
2 & NX & 129.8 & 166.7 \\
3 & NA & 127.1 & 165.3 \\
4 & WA & 125.9 & 166.1 \\
5 & MD & 120.3 & 165.9 \\
\hline
\end{tabular}

polypropylene such as $\mathrm{T}_{c}$ on $, \mathrm{T}_{c}^{\mathrm{P}}, \mathrm{S}$ values are significantly improved, where the $S$ value represents the initial nucleation rate, and the larger the absolute value is, the faster the crystallization rate goes. By comparison, NX nucleating agent has the best effect on increasing crystallization rate, the $\Delta \mathrm{T}_{\mathrm{c}}$ value is the smallest, the $\mathrm{S}$ value is the largest, and the semi-crystallization time is the shortest.

\subsection{Effect of nucleating agent on crystallization temperature of polypropylene}

The melting and crystallization behavior of polypropylene were measured by DSC method. The melting temperature $\mathrm{T}_{\mathrm{m}}$ and crystallization temperature $\mathrm{T}_{\mathrm{c}}$ of modified PP are shown in Table 6.

Nucleating agents significantly increases the crystallization temperature of polypropylene (Table 6). 
In addition, because the nucleating agent reduces the nucleation free energy, the polypropylene is crystallized at a high temperature, the crystallization is more perfect, and the crystallization melting point is higher, wherein the nucleating agent NX has better effect on improving the crystallization and melting temperature of the polypropylene.

\subsection{Effect of nucleating agent on spherulite size of polypropylene}

In order to verify the change of nucleating agent on the spherulite size of polypropylene, the crystal size was characterized by XRD.

The average grain diameter size of each PP and nucleated PP was calculated according to the above Eq. 8 and 9, as shown in Table 7.
Nucleating agent can change the spherulite size of polypropylene, increase the crystallization rate and decrease the spherulite size.

According to Eq. 10, crystal nucleus density of polypropylene were calculated, as shown in Table 8.

From Table 8 (nucleated PP spherulite size and nucleation density), we can see the crystal nucleus density of the modified polypropylene increases and

Table 8: Nucleated PP spherulite size and nucleation density.

\begin{tabular}{llllll}
\hline No & $\mathbf{1}$ & $\mathbf{2}$ & $\mathbf{4}$ & $\mathbf{5}$ & $\mathbf{6}$ \\
\hline Type of nucleating agent & Pure PP & NX & NA & WA & MD \\
Spherulite size $/ \mathrm{nm}$ & 87.59 & 40.36 & 57.22 & 66.55 & 75.69 \\
Crystal nucleus density $\times$ & 2.84 & 29.06 & 10.19 & 6.48 & 4.40 \\
$10^{12} / \mathrm{cm}^{-3}$ & & & & & \\
\hline
\end{tabular}

Table 7: X-ray diffraction and calculating spherulite nucleating diameter.

\begin{tabular}{|c|c|c|c|c|c|}
\hline No & Peak position & $\begin{array}{r}\text { Diffraction } \\
\text { angle }(2 \theta) /^{\circ}\end{array}$ & $\begin{array}{r}\text { half-peak } \\
\text { width }(\beta) /{ }^{\circ}\end{array}$ & $\cos (\theta)$ & $\begin{array}{r}\text { crystal grain } \\
\text { diameter (D)/nm }\end{array}$ \\
\hline \multirow{6}{*}{ Pure PP } & 1 & 13.98 & 0.32 & 0.992 & 24.34 \\
\hline & 2 & 16.77 & 0.54 & 0.989 & 14.66 \\
\hline & 3 & 18.49 & 0.45 & 0.987 & 17.77 \\
\hline & 4 & 21.02 & 0.29 & 0.983 & 27.59 \\
\hline & 5 & 21.75 & 0.53 & 0.982 & 15.01 \\
\hline & Average & & & & 19.87 \\
\hline \multirow{6}{*}{ NX } & 1 & 13.96 & 0.58 & 0.992 & 13.66 \\
\hline & 2 & 16.75 & 0.47 & 0.989 & 16.94 \\
\hline & 3 & 18.52 & 0.87 & 0.986 & 9.20 \\
\hline & 4 & 21.01 & 0.62 & 0.983 & 12.85 \\
\hline & 5 & 21.76 & 0.55 & 0.982 & 14.68 \\
\hline & Average & & & & 13.47 \\
\hline \multirow{6}{*}{ NA } & 1 & 13.92 & 0.69 & 0.992 & 11.58 \\
\hline & 2 & 16.73 & 0.41 & 0.989 & 19.21 \\
\hline & 3 & 18.54 & 0.79 & 0.986 & 10.15 \\
\hline & 4 & 21.00 & 0.30 & 0.983 & 26.59 \\
\hline & 5 & 21.71 & 0.64 & 0.982 & 12.56 \\
\hline & Average & & & & 16.02 \\
\hline \multirow{6}{*}{ WA } & 1 & 13.92 & 0.70 & 0.992 & 11.34 \\
\hline & 2 & 16.73 & 0.44 & 0.989 & 18.01 \\
\hline & 3 & 18.51 & 0.68 & 0.986 & 11.74 \\
\hline & 4 & 21.00 & 0.31 & 0.983 & 25.50 \\
\hline & 5 & 21.68 & 0.68 & 0.982 & 11.86 \\
\hline & Average & & & & 15.69 \\
\hline \multirow{5}{*}{ MD } & 1 & 14.24 & 1.76 & 0.992 & 4.54 \\
\hline & 2 & 15.89 & 0.34 & 0.990 & 23.12 \\
\hline & 3 & 16.72 & 0.41 & 0.989 & 19.17 \\
\hline & 4 & 20.96 & 0.33 & 0.983 & 23.91 \\
\hline & Average & & & & 17.69 \\
\hline
\end{tabular}


the spherulite size decreases. The nucleating agent NX modified polypropylene has the smallest spherulite size and the largest crystal nucleus density, which indicates that the nucleating effect is the best.

\section{Conclusions}

Different kinds of nucleating agents have great influence on the crystallization kinetics, the crystalline morphology and crystallinity of polypropylene. Since NX nucleating agent structure is similar to the size of the propylene, the crystallization time and crystallization temperature of polypropylene reach the highest, 53.4 seconds and $129.8^{\circ} \mathrm{C}$ respectively. At the same time, nucleating agent significantly reduces the nucleation free energy of polypropylene and the sperodidal size, and promotes the high temperature crystallization of polypropylene. According to XRD calculation, NX nucleating agent is the best, and the spherulite size is the smallest, which is $40.36 \mathrm{~nm}$.

\section{References}

1. Mathieu C., Thierry A., Wittmann J.C., Lotz B., "Multiple" nucleation of the (010) contact face of isotactic polypropylene, a phase. Polymer, 2000, 41(19), 7241-7253.

2. Stocker W., Schumacher M., Graff S., Thierry A., Wittmann J.C., Lotz B., Epitaxial crystallization and AFM investigation of a frustrated polymer structure: Isotactic poly(propylene), $\beta$-phase. Macromolecules, 1998, 31(3), 807-814.

3. Dorset D.L., McCourt M.P., Kopp S., Schumacher M., Okihara T., Lotz B., Isotactic polypropylene, $\beta$-phase: A study in frustration. Polymer, 1998, 39(25), 6331-6337.

4. Thierry A., Straupe C., Lotz B., Wittmann J.C., Physical gelation: Apath towards ideal dispersion of additives in polymers. Polym Commun, 1990, 31(8), 299-301.

5. Fillon B., Lotz B., Thierry A., Wittmann J.C., Self-nucleation andenhanced nucleation of polymers. Definition of a convenientcalorimetric "efficiency scale" and evaluation of nucleatingadditives in isotactic polypropylene( $\alpha$ phase). J Polym Sci Pol Phys, 1993, 31(10), 1395-1405.

6. Xu Z.Q., Influence of $\alpha$-nucleating agents on crystallization behavior of ultra-high impact polypropylene and its composites. Plastics Science and Technology, 2016, 44(2), 21-24.

7. Qian W., Guo S.H., Wang J.Q., et al., Preparation of imide $\beta$-nucleating agent and effect on properties of polypropylene. Plastics, 2016, 45(2), 30-33.

8. Papageorgiou D.G., Chrissafis K., Bikiaris D.N., $\beta$-Nucleated polypropylene processing properties and nanocomposites. Polym Rev, 2015, 55, 1-34.

9. Zhang X.L., Zhang P.S., Zhu B.C., et al., Research progress in the $\beta$ nucleating agent for potypropylene. China Synthetic Resin and Plastics, 2015, 32(5), 68-76.
10. Dou G.R., Dou Q., Melting crystallization behaviors and mechanical properties of IPP modified by $\beta$ nucleating agents. Modern Plastics Processing and Applications, 2015, 27(2), 39-42.

11. Huo H., Jiang S., An L., Influence of shear on crystallization behavior of the $\beta$ phase in isotactic polypropylene with $\beta$-nucleating agent. Macromolecules, 2004, 37, 2478-2483.

12. Song S., Feng J., Wu P., Yang Y., Shear-enhanced crystallization in impact-resistant polypropylene copolymer: influence of compositional heterogeneity and phase structure. Macromolecules, 2009, 42, 7067-7078.

13. Kristiansen M., Werner M., Tervoort T., Smith P., The binary system isotactic polypropylene/bis(3,4-dimethylbenzylidene) sorbitol: phase behavior, nucleation, and optical properties. Macromolecules, 2003, 36, 5150-5156.

14. Wang S.C., Zhang J., Effect of nucleating agent on the crystallization behavior, crystal form and solar reflectance of polypropylene. Sol Energ Mater Sol C, 2013, 117, 577-584.

15. Zhang X.J., Zhang D., Liu T., Influence of Nucleating Agent on Properties of Isotactic Polypropylene. Energy Proced, 2012, 17(B), 1829-1835.

16. Gomes Simanke A., de Azeredo A.P., de Lemos C., Santos Mauler R., Influence of nucleating agent on the crystallization kinetics and morphology of polypropylene. Polímeros, 2016, 26(2), 1678-5169.

17. Dolgopolsky I., Silberman A., Kenig S., The effect of nucleatingagents on the crystallization kinetics of polypropylene. Polymer for Advanced Technologies, 1995, 6(10), 653-661.

18. Blanco I., Abate L., Antonelli M.L., The regression of isothermal thermogravimetric data to evaluate degradation Ea values of polymers: A comparison with literature methods and an evaluation of lifetime prediction reliability. Polym Degrad Stabil, 2011, 96(11), 1947-1954.

19. Supaphol P., Charoenphol P., Junkasem J., Effect of nucleating agents on crystallization and melting behavior and mechanical properties of nucleated syndiotactic poly(propylene). Macromol Mater Eng, 2004, 289(9), 818-827.

20. Deyan S., Application of infrared spectroscopy in polymer research. Beijing Science Press, 1982, 163-165.

21. Xingrong Z., Polymer modern test and analysis technology. Guangzhou South China University of Technology Press, 2007, 295-296.

22. Bu H.S., Wunderlich B., et al., Macromol Chem Rapid Commun, $1988,76$.

23. Jeziorny A., Parameters characterizing the kinetics of the nonisothermal crystallization of poly(ethylene terephthalate) determined by d.s.c. Polymer, 1978, 19, 1142.

24. Xu X.R., Xu J.T., Chen L.S., Liu R.W., Feng L.X., Nonisothermal crystallization kinetics of ethylene-butene copolymer/ low-density polyethylene blends. J Appl Polym Sci, 2001, 80, 124 .

25. Avrami M., Kinetics of Phase Change I General Theory. J Chem Phys, 1939, 7, 1103-1112.

26. Avrami M., Kinetics of phase change II Transformation-timerelations for random distribution of nuclei melvin avrami. J Chem Phys, 1940, 8, 212-224.

27. Avrami M., Kinetics of Phase Change III Phase change and microstructure. J Chem Phys, 1941, 9, 177-184.

28. Williamson G.K., Hall W.H., X-Ray Line Broa Dening from Filed Aluminium and Wolfram. Acta Metall, 1953, 1, 22-31. 